\title{
Through the Eyes of Mad Men
}

Simulation, Interaction, and Ethics

\section{Mitchell Aboulafia}

\section{(2) OpenEdition}

Electronic version

URL: http://journals.openedition.org/ejpap/828

DOI: $10.4000 /$ ejpap.828

ISSN: 2036-4091

\section{Publisher}

Associazione Pragma

\section{Electronic reference}

Mitchell Aboulafia, «Through the Eyes of Mad Men», European Journal of Pragmatism and American Philosophy [Online], III-2 | 2011, Online since 29 December 2011, connection on 19 April 2019. URL: http://journals.openedition.org/ejpap/828 ; DOI : 10.4000/ejpap.828

This text was automatically generated on 19 April 2019.

\section{c) (†) $९$}

Author retains copyright and grants the European Journal of Pragmatism and American Philosophy right of first publication with the work simultaneously licensed under a Creative Commons AttributionNonCommercial-NoDerivatives 4.0 International License. 


\title{
Through the Eyes of Mad Men
}

\author{
Simulation, Interaction, and Ethics
}

\author{
Mitchell Aboulafia
}

\section{AUTHOR'S NOTE}

A version of this article was presented as the Keynote Address at the 65th Annual Mountain-Plains Philosophy Conference, Denver, Colorado, October 2011. I wish to thank Candice Shelby and Catherine Kemp for their suggestions.

1 Not long ago I began to read in earnest about the simulation and theory theory or folk psychology debate in cognitive science. I was led to this debate in researching contemporary approaches to agency in social psychology. Quite coincidently I found myself watching the television series Mad Men. For those of you unfamiliar with the series, the title refers to the ad men primarily on Madison Avenue in the 1960's. How fortunate, I thought, to be watching a show about a profession in which the name of the game is simulation or mindreading of a sort, and not only from individual to individual but from individual to groups. If anyone has a better than average ability to mindread for example, to determine the beliefs and predict the decisions of others - it would be these folks. Now I realize that there is a danger of confusing fiction with fact by appealing to a TV series, but good fiction, which by and large this series has been, is often nuanced in dealing with interpersonal relationships, consolidating our own experiences in wellcrafted scenes. Such scenes can help to illuminate theories of mindreading in a manner that parallels more traditional thought experiments. And let me assure the reader in advance that my use of Mad Men will not require you to have watched the show.

2 I will address important features of simulation theory in order to argue that many of its most valuable insights can be found in a tradition influenced by George Herbert Mead. But my interests here are not merely antiquarian. I intend to show that a neo-Median model of how we relate to others can highlight weaknesses in simulation theory. It can also assist in addressing ethical questions in a more sophisticated and comprehensive way than simulation theory, whether it is the hybrid model defended by Alvin I. Goldman 
or the transformation approach of Robert M. Gordon. My goal is to entice readers into considering how a neo-Meadian framework might offer a productive path for future reflections and research in ethics.

3 Before drawing on some examples from Mad Men to illustrate aspects of simulation theory, it's appropriate to let two influential simulation theorists say a few words about how they view their models. We turn first to Alvin Goldman and his understanding of the differences between simulation theory and theory theory, and then to Robert Gordon. Of course their positions contain nuances that can't be captured by relatively brief quotations. Nevertheless, these carefully crafted summary statements will help to set the stage. I quote first from Goldman's response to criticisms of his book, Simulating Minds, made by Perner and Brandl.

Suppose an attributor wishes to mindread a target's decision. If she uses simulation, she will generate a "pretend" decision of her own, extract that decision, and project it onto the target. If she uses theory, on the other hand, she will not produce a pretend - or genuine - decision at all. She will form a belief about the target's decision, based on purely factual or theoretical reasoning from her (the attributor's) beliefs about the targets prior preferences, prior beliefs, and psychological laws. (Goldman 2009: 478)

Early in his recent book, Simulating Minds, Goldman spells out his understanding of the basics of simulation with regard to decision making in this way.

Predicting another's decision is a stock example that ST aims to explain. It says that an attributor goes about this task by imaginatively putting herself into the target's shoes. She pretends to have the same initial states - for example, the same desires and beliefs - and then makes a decision given those initial, pretend states. Having made a decision in the pretend mode, the attributor predicts that this is the decision that the target will make. (Goldman 2006: 19)

5 Properly speaking this sort of mindreading - one that involves pretence, imagination, and prediction - is high-level simulation. This is distinguished from low-level simulation, which is a relatively primitive form of simulation for Goldman, one that involves, for example, reading basic emotions from facial expressions. This distinction is not accepted by all simulation theorists. Further, Goldman is challenged by one of the parents of simulation theory regarding a basic feature of his account. According to Robert Gordon, simulation doesn't involve turning to one's own mental states in order to help determine what the other is thinking. Gordon understands simulation in terms of the transformation of oneself into the other. The exemplary case is that of the actor who transforms himself into the character he is playing. Shaun Gallagher presents Gordon's position in the following fashion.

I do not retreat introspectively to my own mind to run simulation routines by manipulating propositional attitudes like beliefs and desires. Rather, I put myself in the other person's perspective and look to see what she thinks is true about the world. This involves a transformation that takes place on the personal level. By using my imagination, I imagine/simulate what the other person must think in her situation. I do not imagine myself in her situation; I imagine her in her situation, by imaginatively occupying her situation. The transformation involves an egocentric shift, but does not involve either introspection of my own mental states, or inference making about the other's mental states. I am not concerned with mental states at all. I imagine, in the first-person, how the other person sees the world. (Gallagher 2007: 66-7) 
Gordon's position can be seen as responding to Daniel Dennett and others who have claimed that Goldman's model is open to the standard critiques that have been leveled against approaches to mindreading that employ analogy. In Gordon's words,

One reason I emphasize transformation is that a number of writers, both pro and con the simulation theory, take simulation to involve an implicit inference from oneself to others. It is essentially the old argument from analogy, which requires that you first recognize your own mental states, perhaps under certain imagined hypothetical conditions, and then infer that the other is in similar states. (Gordon 1995: 734)

7 Needless to say, Goldman has a retort, and is unwilling to cede ground on the importance of some form of introspection for the simulation process. In responding to Gordon, he states, "Thus, as I interpret ST, it naturally invites an introspective approach to firstperson attribution [...]. [T]here is empirical evidence that third-person mindreading involves use of a brain region responsible for self-reference or self-reflection" (Goldman 2006: 187).

Having briefly outlined some of the features of simulation theory, and with caveats that Goldman views his theory as a hybrid, employing both simulation and folk psychology, and that Gordon is quite prepared to acknowledge that hypothetical reasoning has a place in mindreading, we turn to Mad Men. ${ }^{1}$

9 The central character in Mad Men is Don Draper. He is a whiz at figuring out what will motivate people to buy products. But his talent appears to be mysterious to his colleagues. They stand in awe of how quickly he can determine the right move. We, the audience, have more information about Don than do his colleagues. We know that Don Draper was originally born Dick Whitman. We know that he has lived most of his adult life under an assumed name. We also know enough about his biography - his traumatic childhood, his abusive father - to suggest why he might be so good at his job. He is a person who has had to pay close attention to others in order to survive, first as a child and then as an adult pretending to be someone else. There are four scenes from the show that I wish to discuss, three directly involving Don.

Scene one (Mad Men, 2009A). Conrad Hilton has called Don to his hotel suite. They had met at a party but Don didn't know at the time that the man behind a bar, Connie, was Conrad Hilton. It seems that Connie has now tracked him down and wants to talk. He suspects that Don might be really good at his profession. This could be big business for Don. It's Hilton, after all. Within minutes of entering the suite, Connie wants Don to give him advice on an ad campaign. Don resists. He says to Connie, "I think that you wouldn't be in the presidential suite right now if you worked for free." Hilton pushes back. "Don, this is friendly." Don retorts, "Connie, this is my profession; what do you want me to do?" Connie wants him to give him one for free. The mock-ups for the ads are right in front of them on the coffee table. Don lights a cigarette and takes an effortless look. They show hotels with friendly mouse mascots in the foreground. Don briefly pauses and then states his view. "I don't think anyone wants to think about a mouse in a hotel." Hilton realizes that Don is obviously right, even though he admits that the ad campaign was his idea. Chagrined, he asks, "You got something better?." And the courting dance continues.

11 Here is the background for the second scene that we want to consider. The staff in the office of Don's agency becomes aware that there has been a terrible crash of an American Airlines plane in NY. Presumably everyone is lost. There is black humor around the office about the crash. One of the executives at the agency, Duck, claims to have a personal 
relationship with a high level executive at American Airlines. Duck knows that American Airlines is very worried about how the crash will affect the company. He believes that they will be looking for a new ad agency. He also believes that their agency can hook them. In a horrible twist of fate, one of the most ambitious young executives in the office, Pete Campbell, learns that his father, with whom he did not get along, died in the crash. In spite of this loss, Duck wants Pete to join him in a meeting with his contact, Shel, at the university club. Pete, naturally, feels very uncomfortable. He doesn't think he can do it.

The scene that we wish to consider opens with Duck sitting in the university club with Shel (Mad Men, 2008). The lighting is low and they are comfortably ensconced in leather chairs, drinks nearby. But things are not going well. Shel is hedging, claiming that it's going to be tough to switch to a new agency. Then Pete shows up. Duck introduces him to Shel as his agency's best. Shel reiterates, we don't know where we are yet. Pete tries a typical sales pitch, asserting how enthusiastic they are about working with American Airlines. Shel is not moved. And then Pete says, "We understand how delicate the process of rebuilding the public's confidence will be." Shel responds, "It's not just the public, our stock holders." Pete replies, "I want you to know that should you decide to bring us your business there will be someone on your account who knows exactly what you are going through [...] My father was on that plane." Shel is shaken and moved. It is something he will pass on, that is, report to his colleagues. The audience is left with the impression that Pete's revelation might have helped salvage the deal.

Scene three doesn't involve the agency (Mad Men, 2009B). It takes place in an elementary school classroom. Don and his wife, Betty, have been called in for a teacher's conference because their daughter, Sally, has been acting out and fighting in school. Betty is very pregnant and quiet. She clearly looks depressed, even pained. The teacher, Susan, is young and earnest. She presses Don and Betty about their daughter's behavior. Betty, coolly emotional, reports, "My, um, father passed away (pause) last week, week before, two weeks now." Susan becomes agitated and extremely apologetic. She walks over and holds Betty's hand, saying, "I feel terrible for bringing that up for you." Susan then asks, "Is this grandpa Gene we are talking about? Uh, that poor thing." (Referring to their daughter). If only she (Susan) had known. How horrible! Susan continues, "Now I know why she was asking all of those questions about Medgar Evers' murder." Betty leaves the room and Susan discusses how Sally needs more attention with Don. She says that Sally is grieving. Of course she now understands their daughter's behavior. Susan tells Don, "There is a special pain to losing someone at that age. I don't know if you can understand that." Don responds with a simple, "I can." Betty returns.

The fourth scene is a follow-up to the classroom exchange (Mad Men, 2009B). That evening Susan calls Don and Betty at home. Don answers. The camera shifts back and forth from Don to Susan. Susan is smiling at first with a drink in hand. She has called to apologize about their meeting. Don wonders why. Susan becomes very serious. "My father died when I was eight and I might have overdone it relating to Sally in that way [...] I guess I can get caught up in things and lose perspective." (There is a subtext here. Susan and Don appear to be attracted to each other, which adds further complexity to the interactions in the classroom, but we will pass on them here).

In terms of how these scenes relate to simulation theory, let's start with the classroom scene first. If Goldman were to apply simulation theory to the people in this scene, it is unlikely that he would focus solely on low-level emotional simulation, which typically involves the presence of the person to whom one is responding. Susan, the teacher, seems 
to be reacting to Betty in this fashion, although it is possible to interpret her reaction to Betty as also involving higher level simulation. But it is not Betty's state that is the most obvious target for a higher level simulation. It is her daughter's. The teacher uses her own feelings and beliefs, her own mental state, to help ascertain how Betty and Don's daughter must be feeling because of the loss. Yet on reflection Susan is aware that she may have overreacted due to the loss of her father as a child. Besides violating the rules of decorum, she may not have simulated Sally correctly, and she definitely failed to simulate Don's state of mind. He had in fact experienced the loss of his father as a child. If simulation is a process that is mediated by one's own mental states, then there is always the possibility of misreading or failure due to an egocentric bias, according to Goldman. And this raises the issue of projection, which Goldman addresses.

I shall call the act of assigning a state of one's own to someone else projection [...] [P]rojection is a standard part of the ST story of mindreading. It is the final stage of each mindreading act, a stage that involves no (further) simulation or pretense. Indeed, it typically involves an "exit" from the simulation mode that occupies the first stage of a two-stage routine. (Goldman 2006: 40)

But if projection is a basic feature of ST, and if the model is best understood as simulation plus projection, how are we to avoid egocentric biases? There must be some mechanism that prevents us from getting too carried away with our own beliefs and emotions, as did Susan, when we are seeking to mindread. For Goldman the answer is that we quarantine "genuine states that don't correspond to states of the target," thereby keeping them out of the simulation. If they should intrude, "biases are likely to result. If leakage or quarantine failure is rampant, egocentric biases will also be rampant" (Goldman 2006: 41). Further, while simulation requires a projection stage, it is possible that we might have projection without simulation. ${ }^{2}$ Preventing unwarranted projections involves inhibition. In Goldman's words,

Quarantine prevents something from happening that might otherwise occur; specifically, it prevents one's own states from being projected onto the target. In neural terms, such prevention is inhibition. It might be described as "inhibiting the self-perspective." If simulation is a major facet of third-person mindreading, successful mindreading should involve inhibition of the self-perspective. (Goldman 2006: 170)

17 Goldman needs "inhibition" for his model to work. But he doesn't actually provide an account of the development of inhibitory mechanisms. In the section of Simulating Minds on egocentrism and projection, he presents us with behavioral studies of egocentric bias that are "interpretable within the projection framework" (Goldman 2006: 165). In the next section, "The Neuropsychology of Quarantine," he turns to a case study involving a stroke victim. Goldman informs us that, "someone impaired in the ability to inhibit the self-perspective should have trouble producing accurate mindreading. This is what ST predicts, and this prediction is dramatically confirmed in the case of a particular stroke patient" (Goldman 2006: 170). The damage done to this stroke victim was in a region of the brain that one study "highlighted as possibly sustaining the ability to inhibit one's own perspective" (Goldman 2006: 171). So we have the case study of one patient (WBA), who is having problems inhibiting her own perspective, who has suffered damage to a region of the brain, a region which possibly has something to do with inhibiting one's own perspective, according to another study. Goldman concludes from these two studies, "it is natural to infer that inhibition of self-perspective is a vital aspect of mindreading" (Goldman 2006: 172). ${ }^{3}$ Something like the inhibition of self-perspective may very well be a part of mindreading, but one case study and one study of a brain region isn't solid 
evidence. At best Goldman has suggestive results that may point to a necessary condition, a part of the brain that needs to be functioning in order for $\mathrm{x}$ to happen, without an explanation of $x .{ }^{4} \mathrm{~A}$ mature theory of how inhibition develops is never presented. ${ }^{5}$ And such a theory would at minimum have to address what an effective, as opposed to "accurate," simulation would mean in different cultural and social contexts, because what we inhibit is not simply a matter of how accurate, if that is the correct term, we need to be, but how effective we want or intend to be. ${ }^{6}$ To explore how the intention to be effective might complicate the picture for simulationists, let's return to the first scene.

Recall that Conrad Hilton has asked Don to his hotel suite for some free advice and to test him. Don understands the game. He can't simply give free advice if he is going to be seen as a valuable player. But he accedes to Connie's request anyway. However, he does so only after lighting a cigarette and allowing himself a pregnant pause, as if to say, 'ok, here is your advice, no effort involved'. If we interpret his response in terms of simulation, in evaluating the mock-ups Don would be placing himself in the shoes of prospective hotel guest(s) through imagination, and then after processing his pretend beliefs, he would project them back on to the target, the hotel guest. How would she react? She would be turned off to ads with mice.

Without going into the details of the theory theory versus simulation debate in any depth, I do want briefly to raise the issue here of which model might better explain Don's reaction. According to Joe Cruz and Gordon,

What unifies theory theorists is the view that attributing inner states and making sense of the behavior of others is carried out by a capacity that deploys knowledge encoded in a theory. The most straightforward sense in which ST is opposed to TT is that simulation theorists deny that our capacity to attribute mental states is subsumed by a body of knowledge about the minds of others. Rather, our own mental processes are treated as a manipulable model of other minds. (Cruz \& Gordon 2005)

So perhaps Don didn't simulate hotel guests at all. Perhaps he simply inferred, relatively quickly, from his knowledge of people and their aversions, that associating a hotel with a mouse is a bad idea. Since both Goldman and Gordon have conceded that we employ theory at times to read others, how are we to decide whether Don did so in this case? In this particular situation I submit that there is no way. He could have used theory or simulation or both. The interaction can't tell us. How might we tell? Well, if you are a certain kind of cognitive scientist you will argue that different regions or networks of the brain may be involved if we are using theory instead of simulation to read a target.

However, what complicates our answer to this question is not only our limited knowledge of the brain but the complexity of the situation itself. If we go back to the scene, we will see that Don is never simply engaged in mindreading in relationship to a prospective hotel guest. He is also seeking to place himself in the best light in relationship to Connie. He needs an effortless and convincing answer. Perhaps there wasn't any simulation or theory in play at all regarding the hotel guests. Perhaps it was all a show for Connie. Don has read Connie through his knowledge of men of a certain age and class background, etc., and/or he has read his facial expressions and body language, allowing him to simulate features of Connie's emotional state. He concluded that any assertive answer was better than none. After all, Don had a strategic intention. His goal was not to mindread prospective guests but to convince Connie. Or possibly there wasn't any theory or simulation involved in his response, only behavioral cues, ones that he may have been little aware of, but which still allowed him to make the call. Yet even if this was all that he 
was doing, he was in some sense taking the perspective of the other, although not through simulation or theory. His perspective taking might better be viewed as a form of interpersonal praxis, about which I will have much to say shortly. In any case, it is important to note that there was a strategic dance between Don and Connie, one that probably involved multiple sorts of interactions, some better understood in terms effective interaction rather than accurate simulation. ${ }^{7}$

There is a group of social psychologists, several at Simon Fraser University, who have developed a neo-Meadian approach to agency, in part in response to TT and ST. At first it may be somewhat difficult to see just how they differ from the simulation theorists. There is an extraordinary emphasis in their framework on taking the perspective of the other, which can be framed in terms of stepping into the other guy's shoes, an expression which Goldman and other simulationists often use. And like the simulationists they often cite studies that show how infants are interactive and engage in incipient intentional behavior (e.g., gaze following) from an early age, that is, prelinguistically. But they don't conceptualize our relationship to others in the same fashion. Here is how three of them, Jack Martin, Bryan Sokol, and Theo Elfers, frame the differences.

Whereas simulation and theory theorists tend to think about perspective taking in cognitive and mentalistic terms supported by neurophysiological mechanisms, we locate perspective taking, its emergence, and its development within the coordinated interactivity and conduct of infants, children, adolescents, and adults with objects and others in the biophysical and sociocultural world. For us, the development of our abilities to work with and through perspectives is not an instantiation or stimulation of preexisting mental concepts and structures. It is a situated, embodied, dynamic, and coordinated way of being and conducting ourselves with others and things that moves from a social, interactive to a psychological, intersubjective footing during ontogenesis. However, even with this graduated emergence of more advanced psychological aspects, perspective taking never loses its situated, embodied foundation. As we interact in a world of objects and others, our orientations are constantly shifting, forming, and transforming in interaction with the activities and orientations of others. It is within this ongoing interaction and coordination that the generative processes of our psychological lives are located. (Martin, Sokol, Elfers 2008: 295-6)

Part of the difficulty in distinguishing the approach of the interactionists from that of the simulationists revolves around the phrase "taking the perspective (or role) of the other." Simulationists such as Goldman tend to see this activity in terms of low-level mimicry and emotional contagion, or as an explicit attempt to predict how a target will respond using pretend-states, which appears to involve stepping into the other guy's shoes. Mead incorrectly denied the sort of imitation that we find in infants and young children, an error that neo-Meadians do not make. But Mead does supply us with a distinction that is crucial here. For Mead, taking the perspective or role of the other can be seen as taking the attitude of the other. According to Gary Cook,

We can avoid some of the misleading connotations of the phrase "taking the role of the other" by using in its stead the alternative phrase Mead himself often employs, namely, "taking the attitude of the other." An attitude, he says, consists of a behavioral disposition, a tendency to respond in a certain manner to certain sorts of stimuli, or the beginnings of an action that seek an occasion for a full release or expression. (Cook 1993: 79)

When we see two boxers or fencers feinting and parrying, we might say that they are predicting the decision of the other in order to make a decision of their own. Yet, this is not the sort of decision state that allows time for determining the belief states of the 
opponent. Nor is there simple mimicry taking place. The opponents are taking the attitude of the other in order to respond. There is anticipation of the other but it is not reflective anticipation. So here we have an interactional state that requires a form of taking the perspective of the other but one that is not easily accommodated by the way in which either Goldman or Gordon describe simulation. Of course one can say that they are talking about simulation in terms of mindreading while I am now addressing another phenomenon. This would be a mistake. Much of what they take to be simulation is better described in terms of taking the attitude of the other. And by failing to see perspective taking in attitudinal terms, in addition to mimicry and explicit role taking, we drop out crucial resources for describing how agents navigate social worlds. Further, why should simulationists be allowed to define how the phrase "taking the perspective of the other" is understood.

How might the neo-Meadians' approach cash out in relationship to ST? They would be much more interested in how the dynamic interaction of the agents is responsible for the ways in which they interpret the world and others. Of course this is not to say that there aren't biological, theoretical, and "introspective" factors at play. It is to say that perspective taking, attitude taking, is a process that is in itself transformative. But just to make sure that there is no misunderstanding: the neo-Medians aren't claiming that we don't have well-settled habits and beliefs. If we didn't, we wouldn't be able to anticipate what others might say or do. However, we also know that our anticipations are modified in ongoing interaction, even if only to a modest degree, and this complicates the picture for the simulationists. ${ }^{8}$ Let's turn to the third scene to clarify the differences further.

Pete, the young executive in Don's agency, wants to sign American Airlines. He enters the university club where his colleague, Duck, is meeting with Shel from AA. Both Duck and Shel appear uncomfortable. Duck wants a deal but Shel isn't moving in the right direction. Pete can see that Duck has not made much progress and he begins a traditional pitch: We really want your business and we are excited about the opportunity to work with you. But it's not working. Then the young ad man says, my father was on the plane. Shel is clearly taken aback. But what is he thinking? He seems to know immediately that this piece of information is game changer. If you are a simulationist, you might say that Shel is already placing himself imaginatively in the mind of the young exec, and through recognizing the extent of his loss, he is in a position to hypothesize and conclude that Pete might have a unique vantage point from which to help repair the airline's reputation. Or perhaps Shel cannot dismiss Pete because he is having a sympathetic reaction to his loss, that is, he is having an emotional response. Or perhaps both of these are occurring, that is, sympathy and simulation involving strategic calculation. But for our purposes the key to their interaction is that it is instigated by the shock of the unanticipated. Pete made a tactical decision to use his own tragic circumstances to get business. ${ }^{9}$ The airline executive thinks that he is reading Pete correctly when he starts his first traditional pitch. And then Shel is surprised, no, shocked by Pete's revelation, and he has to recalibrate on hearing the news. But his new reading isn't merely observational. It is attitudinal and interactive. And Pete is also modulating his presentation in reaction to Shel's responses. Feint and parry. In this situation, all of the agents are recalibrating in light of a novel revelation. How often does someone tell you that his father has died in the plane of the company that you represent?

Although this scene involves an extraordinary revelation, the neo-Meadians would argue that less dramatic intrusions of novelty regularly occur in our social interactions and that 
their approach is well suited to addressing these events. Novel situations help people learn to be adaptable and flexible, which in turn assists them in developing their capacity for taking more than one perspective at the same time - or to be more exact, at the practical and functional equivalent of "at the same time." ${ }^{10}$ And learning how to take more than one perspective "simultaneously" in turn allows us to grapple with novel situations. We have here a virtuous circle. As Jack Martin, Jeff Sugarman, and Sarah Hickinbottom note,

For Mead, sociality consists of the ability to occupy two or more different perspectives at the same time. The relation of an organism and an environment is continuously dynamic. The natural and social world consists of a multiplicity of perspectives, any one of which may enter into an organism's field of activity. It is by virtue of the organism's ability to be several things simultaneously, in the sense of taking up (acting within) two or more different perspectives, that the organism is able to deal with emergent events or novel, unexpected occurrences. (Martin, Sugarman \& Hickenbottom 2010: 123-4) ${ }^{11}$

Recall that in at least three of the four scenes that have been described, multiple perspectives were potentially in play, and this more accurately comports with more of our social life than does the taking of the perspective of a specific other regarding a particular belief or emotion. Of course we do the latter but even when engaged with one person there is often a multiplicity of perspectives operative on the horizon, a horizon that we anticipate may shift due to novel reactions. In addition, much of our social life is group life. And here is where the ability to take multiple perspectives is most obviously in play. Without addressing this phenomenon or its implications our ethical reflections are impoverished. This impoverishment can be seen in the manner in which Gordon discusses the relationship between impartiality and empathy or sympathy. ${ }^{12}$ But before turning to Gordon, a few words on Goldman's attempt to join ethics and empathy at the hip are in order.

In his 1993 article, "Ethics and Cognitive Science," as well as in his 1992 presidential address to the Pacific Division of the APA, Goldman demonstrated that he was quite prepared to use the term empathy to describe forms of simulation. (Goldman 1993, 1992). ${ }^{13}$ In Simulating Minds we learn that in ethics empathy probably comes into play at both the level of compassion, care, and concern for the other and at the epistemic level, that is, through helping to clarify what the other may be experiencing (Goldman 2006: 298). Goldman does not claim that empathy can in and of itself make us moral, only that it can be an important component of moral practice if assisted by other tools. For example, one of the problems with focusing on empathy is the danger of parochialism, that is, we tend to be more empathic toward those who are more like us and spatially closer. ${ }^{14}$ To counter this we need to extend our empathetic sensibilities. Goldman uses what he calls enactment imagination, or E-imagination, to explain how we can counter parochialism. "To accurately E-imagine the situation of an anonymous and distant individual, it helps to receive detailed information about that person's life experience and an image of her and her immediate environment. Thus, news coverage of ongoing wars, famines, and other catastrophes are more effective when they supply biographical details of selected individuals, as well as photographs or visual footage" (Goldman 2006: 297-8).

Heightening our empathic responses may play a role in altruistic actions. But presumably we must also defeat our egocentric biases. As we saw, Goldman appeals to the notions of quarantine and inhibition to keep egocentric biases in check. However, there doesn't appear to be a connection between these mechanisms and the social development of the 
self or group dynamics. To his credit, Gordon seeks to tie our ability to distance ourselves from what could be called egocentric biases to our ability to become an other, that is, to a form of sociality, although his model limits his success.

31 In his 1995 paper, "Sympathy, Simulation, and the Impartial Spectator," Gordon must confront a basic problem for his approach. Recall that for Gordon we transform ourselves into the other when we simulate. If transformation is truly successful, we in a sense become the other, as does the actor who is fully engaged in playing a role (Gordon 1995: 734-5). But if we become the other, then we lose the ability to evaluate the other critically, whether we are talking about ethics or other tasks, such as giving advice. How do we avoid falling into this trap? Gordon appeals to Adam Smith for assistance.

According to Smith, rather than simply respond to another's pleasure with pleasure and to another's suffering with suffering, we find ourselves turning our attention to the cause of the other's emotion. We imagine ourselves being in the other's situation, ourselves faced with whatever is causing the other's emotion. Then, in imagination, we respond independently, in our own way, to the imagined cause. (Gordon 1995: 741)

But although Smith is on the right track here he fails to make a distinction that Gordon deems salient, between what the other is experiencing and our own experience. To show this he quotes Smith.

As we have no immediate experience of what other men feel, we can form no idea of the manner in which they are affected, but by conceiving what we ourselves should feel in the like situation. (Gordon 1995: 741)

For Gordon, simply imagining how we would feel would result in our transforming simulation into a form of projection, which would be deadly for his transformational model, and render it especially useless in making ethical evaluations. ${ }^{15}$ What does Gordon propose? We must distinguish "between just imagining being in X's situation and making the further adjustments required to imagine being X in X's situation" (Gordon 1995: 741). In other words, we must separate merely imagining being in someone else's situation from imagining being that person in his or her situation. The latter can lead to an overidentification with the other. I in a sense become the other. The former - that is, merely imagining - allows us to still say, "If I were you, I would [...]," with an implicit, "but I am also not you," factored in. If we perform both of these operations, we can then compare our responses. In Gordon's words, "If your response is the same in each case, approve X's conduct; if not, disapprove" (Gordon 1995: 741). He goes no further with this analysis and moves on to the problem of self-judgment, to which we will turn momentarily. He seems to think that it is enough that he has provided us with a decision procedure. How a rift between these two imaginary states provides an impartial vantage point is never addressed. So in spite of the title of the article, with its promissory note of addressing impartiality, what Gordon appears to be offering us is a method for holding back so that we don't immediately assent to the actions of others. Or as he has told us earlier, "unlike the explanation or prediction of behavior, moral assessment requires holding back" (Gordon 1995: 740). If we don't hold back we may find ourselves flooded by the other's emotion and unable to judge. But while the activity of holding back may be of assistance, it certainly doesn't produce impartiality, even if we define the term generously. ${ }^{16}$

Gordon tells us that there is one problem with the analysis he presented regarding the decision procedure. How can we handle judging ourselves? We can't use our own beliefs or conduct as we might when we judge someone else, for it is our own conduct that we 
may have to disapprove. Again, he turns to Smith for assistance and quotes the following passage from The Theory of Moral Sentiments.

When I endeavor to examine my own conduct [...] I divide myself, as it were, into two persons; [...] I, the examiner and judge, represent a different character from that other I, the person whose conduct is examined into and judged of. The first is the spectator, whose sentiments with regard to my own conduct I endeavour to enter into, by placing myself in his situation, and by considering how it would appear to me, when seen from that particular point of view. The second is the agent, the person whom I properly call myself. (Gordon 1995: 741-2; Smith 1976: 113)

It's obvious for Gordon that in simulating someone else I can "be out of sympathy with myself" (Gordon, 1995: 742). ${ }^{17}$ The problem for him is how can I distance myself from my own emotions and motivation when I am the spectator "with my selfsame emotions and motivation" (Gordon 1995: 742). In answering this question Gordon ends his article with the following words,

It can happen only if the very process of becoming a spectator, and of coming to regard myself as an other, changes me. I believe that the process does change us, and that this was Smith's contention, too. But the topic is a complex one: observing myself trying to argue the case in a paragraph or two, I see a lot of hand waving. So I will not try. Q.E.D. (Gordon 1995: 742)

Yes, too cute and clever by half. But Gordon was actually on to something here, although I cannot locate any place in which he followed up on this discussion. In response to Gordon's words, a neo-Meadian would say: precisely, the process does change us. For example, an impartial spectator would never have arisen without the to and fro of perspective taking, although this is not the only condition. ${ }^{18}$ Mead refers to the ability to place oneself between two perspectives, or systems, as sociality. And it includes the experience of being "caught" or suspended between one's own perspective and that of another. This is indeed transformative and we learn how to do this as socially interactive or transactive persons. We are self and other, and can be both self and other. But ST, in either Goldman's or Gordon's versions, is not the best way to capture this interactivity because it is grounded in a model of subjectivity that views the self as requiring a bridge whether it is one of emotional contagion, imagination, or theory - to overcome the self's separation from the other. No doubt we employ these mechanisms in interacting but we don't require them in the manner that Goldman and Gordon suggest. ${ }^{19}$ Briefly here is how Mead and the neo-Meadians would tell the story.

For Mead, the taking of the perspective of others is the condition for the possibility of self-consciousness and self-criticism. Through the reflexivity involved in linguistic interaction the capacity for perspective-taking is nurtured, although it certainly has proto-versions in the interactivity of infants. Specifically, Mead addresses the importance of the vocal gesture in setting the stage for the reflexivity that is made possible by roletaking. For neo-Meadians there is a smooth trajectory from infant interactions through early symbolic interactions. In learning to speak one must be able to hear the other as one hears oneself. This proto-role taking sets the stage for taking the perspective of others in more complex social interactions that we call roles. In order to play roles, we must be able to take the position of the other, as well as our own, and invert them. This is a form of stepping into the other guy's shoes but it is interactive from the get-go. As interactions increase we develop a capacity for taking multiple perspectives. Mead uses the game to illustrate this. If I am playing baseball, and I am the pitcher or third baseman, in order to play the game I must be able to take the perspective of everyone else on the 
team. Is this mindreading? Not as Goldman understands it. There may not be any introspection at all and yet I am engaged in multiple perspectives. Of course there can be introspection, especially when problems arise. But this phenomenon emerges out of my developing ability to take multiple perspectives. I "see" myself from different perspectives and the perspective of the whole, that is, the generalized other. The latter allows me to see myself or an aspect of myself, depending on how one is defining the self, as if I were the (generalized) other. For neo-Meadians, the taking of multiple perspectives contributes to the development of what might be called an impartial spectator, although as a pragmatist, Mead would never view impartiality as a perfectly calibrated neutrality. There is no view from the mountaintop.

There is much that could be said here about how one can't generate an impartial spectator from Gordon's or Goldman's models, as they stand. This not only has to do with the lack of interactivity in their approaches, which is one of the conditions for generating a sense of impartiality. It is because their models do not provide the tools for addressing how groups enter into our experience as a unique sort of third person, what Mead refers to as the generalized other. Most of the time when interacting in groups I do not simulate a group mind, that is, try to figure out what everyone is thinking or believing. I imbibe its patterns of behavior as I interact within the group. These patterns, which are akin to Bourdieu's habitus, play a fundamental role in generating perspectives that transcend the self/other dynamic. In short, if we want to use the notion of empathy to develop a robust ethical theory, we need to see it in terms of sympathy and interactive perspective-taking ${ }^{20}$. Further, we need to view people as agents, not targets, who will behave unpredictably, and whose unpredictability is factored into their sociality by others. In this way we may avoid viewing empathy as an escape hatch for subjects seeking to break away from the similarly wired black boxes of their own minds.

\section{BIBLIOGRAPHY}

ABoulafia M., (2010), Transcendence: On Self-Determination and Cosmopolitanism, Stanford, Stanford University Press.

BATSON C. D., LISHNER D. A., COOK J. \& S. SAWYER, (2005), "Similarity and Nurturance: Two Possible Sources of Empathy for Strangers," Basic and Applied Social Psychology, 27 (1), 15-25.

соок G., (1993), George Herbert Mead: The Making of a Social Pragmatist, Urbana and Chicago, University of Illinois Press.

CRUZ J. \& R. GORDON, (2005), "Simulation Theory," in Nadel L. (2005), Encyclopedia of Cognitive Science, Hoboken, John Wiley and Sons, on-line edition (no page numbers).

GALLAGHER S., (2007), "Logical and Phenomenological Arguments Against Simulation Theory," in Hutto Daniel D. \& Ratcliff Matthew (eds.), Folk Psychology Re-Assessed, Dordrecht, Springer, 63-78. Goldman A. I., (1992), "Empathy, Mind, and Morals," Proceedings and Addresses of the American Philosophical Association, 66 (3), 17-41. 
Goldman A. I., (1993), “Ethics and Cognitive Science,” Ethics, 103 (2), 337-60.

Goldman A. I., (2006), Simulating Minds: The Philosophy, Psychology, and Neuroscience of Mindreading, Oxford and New York, Oxford University Press.

Goldman A. I., (2009), "Replies to Perner and Brandl, Saxe, Vignemont, and Carruthers,"

Philosophical Studies 144, 477-91.

GORDON R. M., (1995), “Sympathy, Simulation, and the Impartial Spectator,” Ethics 105, 727-42.

MARTIN J., SUGARMAN J. H. \& S. HICKENBOTTOM, (2010), Persons: Understanding Psychological Selfhood and Agency, Dordrecht, Springer.

MARTIN J., SOKOL B. W. \& T. ElfERS, (2008), “Taking and Coordinating Perspectives: From

Prereflective Interactivity, through Reflective Intersubjectivity, to Metareflective Sociality,"

Human Development 51, 294-317.

MAD MEN, (2009A), “Guy Walks into an Advertising Agency," directed by Lesli Linka Glatter, written by Robin Veith and Matthew Weiner, first aired September 20, 2009.

MAD MEN, (2009B), "The Fog," directed by Phil Abraham, written by Kater Gordon, first aired September 13, 2009.

MAD MEN, (2008), "Flight 1," directed by Andrew Bernstein, written by Lisa Albert and Matthew Weiner, first aired August 3, 2008.

PRINZ Jesse, (2006), “The Emotional Basis of Moral Judgment,” Philosophical Explorations, 9 (1), 29-43.

PRINZ Jesse, (2011), “Is Empathy Necessary for Morality?,” in Coplan Amy \& Goldie Peter (eds.), Empathy: Philosophical and Psychological Perspectives, Oxford and New York, Oxford University Press.

SMITH A., (1976), The Theory of Moral Sentiments, D. D. Raphael \& A. L. MacFie (eds.), Oxford, Oxford University Press; reprinted, Indianapolis, Liberty Classics, 1982.

\section{NOTES}

1. If successful advertising utilizes simulation, it does so for strategic reasons. Ad men, mad men, aren't interested in mutual understanding in the manner in which Habermas would define it. No, they are interested in figuring out the other in order to manipulate him or her.

2. "Given our definition of projection, taking a genuine state of one's own and ascribing that state to another is clearly a case of projection. Is it a case of simulation-plus-projection? We might consider it a 'limiting case' of simulation-plus-projection, a case in which the simulation element is null but the projection element is robust" (Goldman 2006: 41).

3. Here is the key paragraph. "Of crucial importance, the evidence from WBA appears to demonstrate that the root of at least some egocentric errors in mindreading is failure to inhibit, or quarantine, self-perspective. This, of course, is precisely ST's story. Because Samson et al.'s evidence about WBA, along with evidence from Vogeley et al. (2001), points to a particular brain region as responsible for this function, it is natural to infer that inhibition of self-perspective is a vital aspect of mindreading" (Goldman 2006: 172). Notice that he gives himself wiggle room at the start of the passage by qualifying the claim with an italicized "some." By the end of the paragraph we have a more general (natural) inference: "inhibition of self-perspective is a vital aspect of mindreading." Both of these remarks must be placed in the context of the manner in 
which he began the discussion. At the start of, "Egocentrism and Projection," he states, "There is an extensive literature on egocentric biases in mindreading, and this section and the next one ["The Neuropsychology of Quarantine"] argue that these egocentric biases are best explained by the simulation-plus-projection model" (Goldman 2006: 164).

4. To make matters worse, instead of providing any further discussion of his own account of inhibition, Goldman then launches into how TT can not account for the finding of "widespread egocentrism" (Goldman 2006: 172-3).

5. In Simulating Minds Goldman also discusses evidence from childhood studies that suggest there is a connection between inhibitory control and performance on false belief tasks. "Problems with standard false-belief tasks are problems with inhibiting the first-person perspective (section 8.4), which should be distinguished from (problems with) adopting a third-person perspective" (292). He notes that there is a study that challenges the connection between false-belief task errors and inhibition. (To counter this study, Goldman appeals once again to the stroke victim.) To be fair to Goldman, there are other features of his model - for example, the inputs used for simulation that could lead to problems that we associate with forms of egocentrism, in spite of the fact that he links projection and egocentrism in the sections of the book discussed above (see, note \#4). However, these would be due to failures in the simulation stage, not to a failure to inhibit selfperspective, which is directly linked to the projection stage. It is the former, understood in terms of empathy, that will play an important role in considering the implications of ST for ethics, while the latter - that is, inhibition - touches on the question of impartiality.

6. The latter would apparently involve "decision procedures" for determining degrees of "accuracy." It's interesting to note that at the beginning of the discussion of egocentrism and projection, Goldman sidesteps the issue of when being influenced by one's own "genuine" states is appropriate. "Projection occurs when a genuine, nonpretend state of the attributor seeps into the simulation routine despite its inappropriateness (as judged by information the attributor possesses). This results in an attribution that is inappropriately influenced by the attributor's own current states (genuine, nonpretend states). I won't try to settle the question of when, exactly, being influenced by one's own genuine states is inappropriate" (Goldman 2006: 165). I would be very curious to know what kind of answer to this question could possibly be envisioned from within his model.

7. Note that in spite of the ambiguities in the situation and alternative explanations, Don's responses could still be interpreted in terms of simulation or theory theory by committed ST or TT theorists.

8. While of course there must be constancy of beliefs and habits if we are to function with others, there must also be an ongoing assumption that others are not thinking or believing what we assume. This pragmatic fallibilism is built into interactions with which we are all familiar. When a parent says that she knows Johnny like the back of her hand in the morning, and then says in the afternoon, "that's my Johnny, you can never figure out what he is going to do next," we don't accuse her of violating the laws of logic. The fact is that both things can well be true. of course we can "predict" or anticipate what others will do but we also quite regularly fail at this. Much of the time we got it right enough to function reasonably well with others. And so-called failures to "mindread" should not be understood in terms of not reading a target properly due to lack of knowledge about inputs and outputs. People are not targets in this fashion. They are persons. As persons one of their leading characteristics is their ability to surprise us, in little ways, for example, that permit conversations to continue, and in big ways.

9. We don't know if he knew in advance that he was going raise his father's death. He may have surprised himself by doing so, which raises another set of questions that we will let pass.

10. By using the phrase "at the same time" here I do not mean to imply that multiple perspectives may not involve split second switches from one to the other. The phrase is meant to suggest the practical and functional reality of taking multiple perspectives at once. 
11. The passage continues, "Because persons are themselves social, their perspective taking may be enhanced greatly by communication with others through significant symbols" (124).

12. Gordon does not make any systematic distinction between empathy and sympathy in the article that we will be discussing (Gordon 1995).

13. Portions of "Ethics and Cognitive Science" (Goldman 1993) are identical to the published version of Goldman's Presidential Address to the Pacific Division of the APA (Goldman 1992).

14. The notion that similarity is a significant factor in how much empathy we feel for strangers has been questioned in an experiment involving age and occupation. See Batson et al. 2005.

15. Smith emphasizes different aspects of sympathy in The Theory of Moral Sentiments. We are not confined to our own feelings nearly as much as this quotation would suggest. See, for example, Smith (1976: 317).

16. It's worth noting here how Goldman and Gordon seem to have opposite problems: one worries about egocentric bias, the other about being overwhelmed by the emotions of the other. Nevertheless, in the end they have a similar weakness. They don't have a developed account of the genesis of judgment as it emerges through social interaction.

17. As mentioned in footnote \#13, Gordon does not systematically distinguish between empathy and sympathy in this article. For the most part this is not problematic given his goals. But note that when he uses the phrase "sympathy with oneself," it would be difficult to replace it with "empathy with oneself." The terms have different connotations in contemporary American English. Using "sympathy" in this context appears to help move Gordon's argument along. The terms should be more carefully distinguished.

18. Psychopaths can successfully take perspectives and yet lack concern for others, in all likelihood due to emotional deficits (see Goldman 2006: 293-4; and Prinz 2006: 32).

19. Sometimes simulationists sound as if they are trying to create a clear telephonic connection between the self and other. But a better metaphor for much of our social lives is the game telephone, in which the original input is rarely identical to the output, as each participant transforms, even if only slightly, the meaning intended in the first person's words. Paradoxically, this suggests how close we are to the other, not how remote, when seen through the interactionist's lens. It seems that the problem of other minds is still setting the stage for the reflections of the simulationists, when it's time to let the "problem" drift off into history, as Dewey would suggest.

20. In a forthcoming article (Prinz 2011), "Is Empathy Necessary for Morality?" Jesse Prinz responds to the question in his title with a fairly resounding, yet qualified, no. It is qualified because he leaves open the possibility that "empathic concern" may well play an important role in morality (Prinz 2011). I view Prinz's piece as a corrective to exaggerated claims for what empathy can accomplish for moral actors, if by empathy we mean a kind of emotional vicariousness, which is what Prinz addresses. There is no doubt that "empathy" has been overplayed in popular, as well as some scholarly, literature of late. However, I would argue that Prinz in turn has overplayed his hand in this article. His definition of empathy is circumscribed; for example, he tells us that, "We cannot empathize with a group, except by considering each member" (Prinz, 17 online version). And his reading of the research appears weighted toward supporting his own model - which emphasizes the importance of non-empathic emotions, for example, guilt and anger - through undermining the role of a type of empathy in morality. Although, I tend to agree with him about the importance of some of the "emotions" he mentions, his model ends up offering us an either/or - empathy or his preferred emotions - in spite of a few caveats here and there that empathy may not be completely without value. He also dismisses in a rather cavalier fashion the merit of a cosmopolitan outlook, which he views in Kantian terms. I hope to address some of the limitations of Prinz's approach in the future. His article is currently available on the web [subcortex.com/]. For an alternative view of cosmopolitanism, see Aboulafia 2010. 


\section{ABSTRACTS}

Traditionally pragmatists have been favorably disposed to improving our understanding of agency and ethics through the use of empirical research. In the last two decades simulation theory has been championed in certain cognitive science circles as a way of explaining how we attribute mental states and predict human behavior. Drawing on research in psychology and neuroscience, Alvin I. Goldman and Robert M. Gordon have not only used simulation theory to discuss how we "mindread," but have suggested that the theory has implications for ethics. The limitations of simulation theory for "mindreading" and ethics are addressed in this article from an interactionist or neo-Meadian pragmatic perspective. To demonstrate the limitations of simulation theory scenes from the television show Mad Men are used as "thought-experiments."

\section{AUTHOR}

\section{MITCHELL ABOULAFIA}

Manhattan College

mitchell.aboulafia[at]manhattan.edu 